\title{
Comparison of the Comprehensive Complication Index and Clavien-Dindo systems in predicting perioperative outcomes following radical nephroureterectomy
}

\author{
Scott Geiger ${ }^{1}$, Neil Kocher ${ }^{1}$, Dan Illinsky ${ }^{1}$, Evanguelos Xylinas ${ }^{2}$, Peter Chang ${ }^{3}$, Lauren Dewey $^{3}$, \\ Andrew A. Wagner ${ }^{3}$, Firas Petros ${ }^{4}$, Surena F. Matin ${ }^{4}$, Conrad Tobert ${ }^{5}$, Chad Tracy ${ }^{5}$, Pierre-Marie Patard ${ }^{6}$, \\ Mathieu Roumiguie ${ }^{6}$, Leonardo Lima Monteiro ${ }^{7}$, Wassim Kassouf ${ }^{7}$, Jay D. Raman ${ }^{1}$ \\ ${ }^{1}$ Division of Urology, Penn State Health Milton S. Hershey Medical Center, Hershey, PA, USA; ${ }^{2}$ Department of Urology, Cochin Hospital, Paris \\ Descartes, CPSC, France; ${ }^{3}$ Division of Urology, Beth Israel Deaconess Medical Center, Boston, MA, USA; ${ }^{4}$ Department of Urology, MD Anderson \\ Cancer Center, Houston, TX, USA; ${ }^{5}$ Department of Urology, University of Iowa, Iowa City, Iowa, USA; ${ }^{6}$ Urology Service, Centre Hospitalier \\ Universitaire de Toulouse, Toulouse, France; ${ }^{7}$ Department of Urology, McGill University, Montreal, Canada \\ Contributions: (I) Conception and design: S Geiger, N Kocher, JD Raman; (II) Administrative support: S Geiger, N Kocher, JD Raman; (III) Provision \\ of study materials or patients: All authors; (IV) Collection and assembly of data: All authors; (V) Data analysis and interpretation: S Geiger, N \\ Kocher, JD Raman; (VI) Manuscript writing: All authors; (VII) Final approval of manuscript: All authors. \\ Correspondence to: Jay D. Raman, MD, FACS. Division of Urology, Penn State Health Milton S. Hershey Medical Center, 500 University Drive, \\ H055, Hershey, PA 17033-0850, USA. Email: jraman@pennstatehealth.psu.edu.
}

Background: Complications can occur following radical nephroureterectomy (RNU) in 20-40\% of patients. The Comprehensive Complication Index (CCI) is an alternative grading system to the ClavienDindo (CD) grading system that aggregates all complications experienced by a patient on a continuous (as opposed to categorical) scale. We investigate whether the cumulative nature of CCI renders it superior to CD in predicting perioperative course after RNU.

Methods: The records of 596 patents who underwent RNU at 7 academic medical centers from 2005 to 2015 were reviewed. Complications occurring within 30 days of RNU were annotated using both the CD and CCI classification systems. Logistic regression was used to determine associations between CD and CCI with perioperative covariates as well as measures of convalescence [hospital length of stay (LOS) and readmission].

Results: A total of 377 men and 219 women with a median age of 71, BMI of 27, and Charlson comorbidity score of 4 were included. Over half underwent a minimally invasive RNU. Median LOS following RNU was 6.0 days (range, 1-37 days) and readmission within 30-days occurred in 45 (8\%) patients. Overall, 136 patients $(23 \%)$ experienced a post-operative complication with 91 having a single complication and 45 with multiple (range, 2-6); 44 (7\%) patients had Clavien III or greater complications, and the median CCI for those patients experiencing a complication was 20.9 (range, 8.7-100). Both the upper quartile of CCI ( $\geq 75$ th $\%)$ and major CD complications were associated with higher baseline Charlson score, ECOG $\geq 2$, and CKD stage $\geq$ III (all $\mathrm{P}<0.05$ ). However, only the upper quartile of CCI was associated with LOS (8.9 vs. 5.4 days, $\mathrm{P}<0.01)$ and hospital readmission (OR 3.2, 95\% CI: 1.9-5.6, $\mathrm{P}=0.02)$ after RNU.

Conclusions: The CD and CCI classification systems both are associated with similar baseline and perioperative characteristics for RNU patients. However, the cumulative nature of the CCI allows for superior prediction of postoperative course after RNU including LOS and readmission.

Keywords: Complications; Clavien-Dindo (CD); Comprehensive Complication Index (CCI); nephroureterectomy

Submitted Oct 15, 2019. Accepted for publication Dec 25, 2019.

doi: $10.21037 /$ tau.2020.01.16

View this article at: http://dx.doi.org/10.21037/tau.2020.01.16 


\section{Introduction}

Upper-tract urothelial carcinoma (UTUC) is an uncommon genitourinary malignancy that accounts for $5 \%$ of urothelial tumors (1). Although presenting infrequently, populationbased studies implicate a steady rise in UTUC incidence over the past three decades (2). The current gold standard for management of bulky, high-grade or muscle-invasive UTUC is a radical nephroureterectomy (RNU) with excision of bladder cuff via a minimally invasive or open approach $(1,3)$. Patients that develop UTUC tend to be elderly and harbor medical comorbidities thereby placing such patients at risk of complications following surgery (4). In fact, rates as high as $30-40 \%$ have been reported from high volume centers that rigorously annotate adverse events.

Historically, complications have been difficult to classify as terminology has been largely inconsistent and poorly standardized. The Clavien-Dindo (CD) scale was first proposed in 2004 and consisted of a five-point scale based on the severity of complication and type of treatment required to remedy the event $(5,6)$. Indeed, the $\mathrm{CD}$ scale has demonstrated correlation with complexity of surgery as well as hospital duration in a large cohort of patients (6). However, this scale lacks a continuous element in its measurement and tends to categorize complications based on the highest severity event.

The Comprehensive Complication Index (CCI) is a newer classification scheme initially proposed in 2013 and provides a continuous (not categorical) scale from 0 to 100 in order to systematically score the severity of any combination of complications (7). This scale proved to be highly sensitive with regards to treatment effect and higher scores correlated with adverse postoperative health status of impacted patients (7).

Patients with urothelial carcinoma are at risk for experiencing treatment related complications. Use of CCI to predict perioperative course in this patient cohort is limited. Specifically, in 2015, Park and colleagues compared the CD and CCI grading systems in a single institution study of 100 RNU patients (8). The authors noted that although both classification schemes were similarly associated with baseline and perioperative characteristics, the CCI more accurately predicted short term recovery after RNU. A criticism of this study, however, was its relatively small sample size which originated from a single institution thereby questioning the generalizability of findings.

Here, we further investigate whether the cumulative nature of the CCI renders it superior to $\mathrm{CD}$ in predicting perioperative course after RNU in a large, international multi-center cohort.

\section{Methods}

Following institutional review board (IRB) approval, the records of 596 consecutive patients who underwent RNU at 7 academic medical centers from 2005 to 2015 were reviewed. Preoperative clinical, demographic, and comorbidity variables included patient age, gender, race, BMI, Charlson comorbidity index (CCI), American Society of Anesthesiologists (ASA) score, Eastern Cooperative Oncology Group (ECOG) performance status, and history of chronic kidney disease. Perioperative variables included surgical approach, length of hospital stay (LOS), and complications and readmissions occurring within 30 days of surgery. Final pathology was confirmed as urothelial carcinoma in all cases.

Perioperative complications were graded using the modified CD classification scale and converted to the $\mathrm{CCI}^{\circledR}$ via the publically available $\mathrm{CCI}^{\circledR}$-calculator (http://www. assessurgery.com/calculator_single/) accessed 12/31/19.

The Wilcoxon Rank Sum and Chi Square tests were used for comparison of continuous and categorical values, respectively. Logistic regression was used to determined associations between CD and CCI with preoperative covariates as well as with hospital length of stay (LOS) and readmissions. Focus was analyzing covariates associated with major CD complications (Clavien III-V) or CCI $>75 \%$ (upper quartile) as these were considered the most clinically significant. Spearman correlation was performed for association of CCI and LOS. SAS version 9.4 was used for analysis.

\section{Results}

Clinical characteristics for the 596 individuals are presented in Table 1. In summary, a total of 377 men and 219 women with a median age of $71, \mathrm{BMI}$ of 27 , and Charlson comorbidity score of 4 were included. Almost $90 \%$ of this cohort were white and over $50 \%$ had baseline chronic kidney disease (CKD) stage III or greater. Over half of cases were performed using a minimally invasive approach. On final pathology, over $60 \%$ of tumors were muscle-invasive, $70 \%$ were high grade, and $8 \%$ had associated positive LNs. Median length of stay (LOS) was 6 days and almost $8 \%$ were re-admitted within 30 days of surgery. 
Table 1 Clinical and pathologic characteristics for 596 RNU patients

\begin{tabular}{|c|c|}
\hline Variable & Values \\
\hline Median age (years) [range] & 71 [27-93] \\
\hline \multicolumn{2}{|l|}{ Gender, n (\%) } \\
\hline Male & $377(63.3)$ \\
\hline Female & $219(36.7)$ \\
\hline \multicolumn{2}{|l|}{ Race, n (\%) } \\
\hline White & 508 (85.2) \\
\hline Black & $38(6.4)$ \\
\hline Other & $43(7.2)$ \\
\hline Not specified & $7(1.2)$ \\
\hline Median BMI $\left(\mathrm{kg} / \mathrm{m}^{2}\right)$ [range] & $26.6[15-58.9]$ \\
\hline Median Charlson Index [range] & $4[0-12]$ \\
\hline \multicolumn{2}{|l|}{ ASA score, n (\%) } \\
\hline$<2$ & $69(11.6)$ \\
\hline$\geq 2$ & $470(78.9)$ \\
\hline Not specified & $57(9.6)$ \\
\hline \multicolumn{2}{|l|}{ ECOG, n (\%) } \\
\hline$<2$ & $385(64.6)$ \\
\hline$\geq 2$ & $89(14.9)$ \\
\hline Not specified & $122(20.5)$ \\
\hline \multicolumn{2}{|l|}{ Pre-op CKD stage, n (\%) } \\
\hline$<\mathrm{III}$ & $254(42.6)$ \\
\hline$\geq I I I$ & $271(45.5)$ \\
\hline Not specified & $71(11.9)$ \\
\hline \multicolumn{2}{|l|}{ Surgical approach, n (\%) } \\
\hline MIS & $318(53.4)$ \\
\hline Open & $220(36.9)$ \\
\hline Not specified & $58(9.7)$ \\
\hline \multicolumn{2}{|l|}{ Pathologic stage, $\mathrm{n}(\%)$} \\
\hline$<\mathrm{pT} 2$ & 329 (55.2) \\
\hline$\geq$ pT2 & $263(44.1)$ \\
\hline Not specified & $4(0.7)$ \\
\hline \multicolumn{2}{|l|}{ Pathologic grade, n (\%) } \\
\hline Low & $167(28.0)$ \\
\hline High & $425(71.3)$ \\
\hline Not specified & $4(0.7)$ \\
\hline Median LOS (days) [range] & $6[1-37]$ \\
\hline Readmission within 30 days, $\mathrm{n}(\%)$ & $45(7.6)$ \\
\hline
\end{tabular}

In total, 136 patients (23\%) experienced a post-operative complication with 91 having a single complication and 45 with multiple (range, 2-6); 44 (7\%) patients had Clavien III or greater complications of which 38 experienced one major complication and 6 experienced multiple major complications. The median CCI for those patients experiencing a complication was 20.9 (range, 8.7-100), and upper-quartile of CCI was 36 . There were 3 deaths $(0.5 \%)$ noted in our cohort within 30 days of RNU.

Table 2 summarizes the univariate model highlighting associations between pre-operative variables and major CD complications as well as upper quartile of CCI. Several similar pre-operative variables were associated with both complication indices including Charlson score, ECOG performance status, baseline renal function, and open surgical approach. Conversely, variables including gender, BMI, and ASA score were not associated with more significant complications.

Variables significant in the univariate model were incorporated into a multivariate model whereby only Charlson score, ECOG performance status, and baseline eGFR were independently associated with both major complications and CCI $>75 \%$ (Table 3 ).

The association of CCI and CD with respect to perioperative recovery metrics including LOS and readmission following RNU were determined by logistic regression. Only the upper quartile of CCI was associated with LOS (8.9 vs. 5.4 days, $\mathrm{P}<0.01$ ) and hospital readmission (OR 3.2, 95\% CI: 1.9-5.6, $\mathrm{P}=0.02$ ) after RNU whilst major $\mathrm{CD}$ complications were not (LOS 7.4 vs. 5.6 days, $\mathrm{P}=0.14$; readmission $\mathrm{OR} 1.4, \mathrm{P}=0.21$ ).

\section{Discussion}

Recognizing the risks associated with radical surgery is an important component of patient counseling, resource utilization, and clinical decision making. To this point, Joudi and colleagues identified 18,575 patients who underwent radical nephrectomy or RNU from 2000 to 2003 and evaluated the impact of complications on length of stay and mortality (8). Not surprisingly, the presence of one or more complications negatively impacted all of these outcomes significantly $(\mathrm{P}<0.001)$ after adjusting for confounding effects.

Due to the significant impact of operative complications on the healthcare system, a standardized and accurate classification system is essential to objectify risk and ultimately guide perioperative management. The CD 
Table 2 Univariate model for association of pre-operative variables with complication indices

\begin{tabular}{|c|c|c|c|c|c|c|}
\hline \multirow{2}{*}{ Variable } & \multicolumn{3}{|c|}{ Major CD complications (grade III-V) } & \multicolumn{3}{|c|}{$\mathrm{CCl}>75$ th $\%$} \\
\hline & Odds ratio & $95 \% \mathrm{Cl}$ & $\mathrm{P}$ & Odds ratio & $95 \% \mathrm{Cl}$ & $\mathrm{P}$ \\
\hline Male gender & 1.08 & $0.73-2.21$ & 0.37 & 1.16 & $0.88-1.88$ & 0.44 \\
\hline BMI (per unit) & 1.18 & $0.93-1.44$ & 0.67 & 1.31 & $0.87-1.51$ & 0.61 \\
\hline Charlson (per 1 unit increase) & 2.97 & $1.98-3.37$ & 0.01 & 2.44 & $1.51-3.67$ & 0.03 \\
\hline ASA score (per 1 unit increase) & 1.05 & $0.92-1.22$ & 0.76 & 1.03 & $0.86-1.19$ & 0.88 \\
\hline Open surgical approach & 1.33 & $1.12-1.92$ & 0.04 & 1.46 & $1.21-2.01$ & 0.01 \\
\hline
\end{tabular}

Table 3 Multivariate model for association of pre-operative variables with complication indices

\begin{tabular}{|c|c|c|c|c|c|c|}
\hline \multirow{2}{*}{ Variable } & \multicolumn{3}{|c|}{ Major CD complications (grade III-V) } & \multicolumn{3}{|c|}{$\mathrm{CCl}>75$ th $\%$} \\
\hline & Odds ratio & $95 \% \mathrm{Cl}$ & $P$ & Odds ratio & $95 \% \mathrm{Cl}$ & $P$ \\
\hline ECOG (per 1 unit increase) & 3.67 & $2.45-6.37$ & 0.008 & 4.22 & $1.78-7.64$ & 0.003 \\
\hline
\end{tabular}

scoring system has been a well-established and recognized tool to classify complications. The principal limitation of this system, however, is categorization based solely on the most serious event. It is hypothesized that the CCI may more accurately reflect the potential post-operative morbidity following procedures due to its ability to capture complications on a cumulative scale.

The primary objective of this study was to utilize multicenter data to compare the CD and CCI classification systems in predicting the perioperative outcomes of patients who underwent RNU. Here, we identified 136 patients (23\%) who experienced a complication, which is consistent with the range found in other peer-reviewed literature (3). When comparing the upper-quartile of CCI and major CD complications, we found that both were associated with higher Charlson score, ECOG $\geq 2$, and CKD stage $\geq$ III.
However, only the upper quartile of CCI was associated with LOS and hospital readmission while major CD complications were not.

The data from this multi-institutional study is consistent with that a prior single center study. Park and colleagues compared CCI and CD classification schemes in a cohort of patients undergoing RNU and showed that (similarly) the upper quartile CCI and major CD complications were both associated with higher Charlson scores $(\mathrm{P}=0.03)$, lower baseline eGFR $(\mathrm{P}=0.005)$, intraoperative transfusion $(\mathrm{P}=0.004)$, open surgical approach $(\mathrm{P}=0.019)$ and symptoms of presentation $(\mathrm{P}=0.019)$. However, only upper quartile CCI was associated with postoperative LOS (8.25 vs. 5.61 days, $\mathrm{P}<0.0001)$ while major $\mathrm{CD}$ complications were not $(7.98$ vs. 6.32, $\mathrm{P}=0.211$ ) (9). A notable criticism of this prior work was smaller sample size and single institution nature 
of the practice which may have impacted findings and observations. Indeed, our larger series underscores those preliminary findings and highlights the value for medical centers to use CCI when tracking convalescence after RNU.

Post-operative complications significantly impact quality and cost-containment metrics such as length of stay and readmission and are one of the most significant contributors to rising healthcare costs (9-11). In the above-mentioned study, Joudi and colleagues noted that the hospital costs associated with radical nephrectomies (including RNU) increased by $33.3 \%$ with one complication and by $84 \%$ with two complications (8). Therefore, to accurately evaluate the risk associated with surgical procedures, it is important to account for the cumulative effect of all complications, rather than just the impact of the most serious event.

Limitations of this study include its retrospective design and perhaps the inconsistency with categorizing complications. Although our study included patients from seven multinational institutions, it may be possible that there are variations in the reporting and treatment of complications. Additionally, we did not have a single author that reviewed all the complications and assigned them a CD grade. Indeed, a systematic review indicated that the CD system was not properly used in $72(35.3 \%)$ urological papers (12). Therefore, having a single reviewer that adequately understands the classification schemes may be necessary to preserve the uniformity in using the CD system. In extension, the validity of the CCI also depends on the accuracy of assigning CD grades to complications, so a standardized protocol is essential. Furthermore, the multinational nature of the study precludes cost analysis of the data particularly given variability in the respective cost of healthcare across different countries.

\section{Conclusions}

The CD and CCI classification systems both have their utility in evaluating baseline and perioperative characteristics for RNU patients. However, the continuous and cumulative nature of the CCI that accounts for complications severity appears to allow for superior prediction of perioperative course following RNU including LOS and readmission.

\section{Acknowledgments}

Funding: The Ken and Bonnie Shockey Fund for Urologic Cancer Research at Penn State Health.

\section{Footnote}

Provenance and Peer Review: This article was commissioned by the Guest Editors (Jay D. Raman and John J. Knoedler) for the series "Upper-Tract Urothelial Carcinoma: Current State and Future Directions" published in Translational Andrology and Urology. The article was sent for external peer review organized by the Guest Editors and the editorial office.

Conflicts of Interest: All authors have completed the ICMJE uniform disclosure form (available at http:// dx.doi.org/10.21037/tau.2020.01.16). The series "UpperTract Urothelial Carcinoma: Current State and Future Directions" was commissioned by the editorial office without any funding or sponsorship. JDR served as the unpaid Guest Editors for the series. The authors have no other conflicts of interest to declare.

Ethical Statement: The authors are accountable for all aspects of the work in ensuring that questions related to the accuracy or integrity of any part of the work are appropriately investigated and resolved. The study was conducted in accordance with the Declaration of Helsinki (as revised in 2013). The study was approved by the Institutional Review Board Informed consent was taken from all individual participants.

Open Access Statement: This is an Open Access article distributed in accordance with the Creative Commons Attribution-NonCommercial-NoDerivs 4.0 International License (CC BY-NC-ND 4.0), which permits the noncommercial replication and distribution of the article with the strict proviso that no changes or edits are made and the original work is properly cited (including links to both the formal publication through the relevant DOI and the license). See: https://creativecommons.org/licenses/by-nc-nd/4.0/.

\section{References}

1. Raman JD, Jafri SM. Complications following radical nephroureterectomy. Curr Urol Rep 2016;17:36.

2. Raman JD, Messer J, Sielatycki JA, et al. Incidence and survival of patients with carcinoma of the ureter and renal pelvis in the USA, 1973-2005. BJU Int 2011;107:1059-64.

3. Hanske J, Sanchez A, Schmid M, et al. A comparison of 30-day perioperative outcomes in open versus minimally invasive nephroureterectomy for upper tract urothelial 
carcinoma: analysis of 896 patients from the american college of surgeons-national surgical quality improvement program database. J Endourol 2015;29:1052-8.

4. Rouprêt M, Babjuk M, Compérat E, et al. European guidelines on upper tract urothelial carcinomas: 2013 update. Eur Urol 2013;63:1059-71.

5. Clavien PA, Barkun J, de Oliveira ML, et al. The ClavienDindo classification of surgical complications: five-year experience. Ann Surg 2009;250:187-96.

6. Dindo D, Demartines N, Clavien PA. Classification of surgical complications: a new proposal with evaluation in a cohort of 6336 patients and results of a survey. Ann Surg 2004;240:205-13.

7. Slankamenac K, Graf R, Barkun J, et al. The comprehensive complication index: a novel continuous scale to measure surgical morbidity. Ann Surg 2013;258:1-7.

8. Joudi FN, Allareddy V, Kane CJ, et al. Analysis of

Cite this article as: Geiger S, Kocher N, Illinsky D, Xylinas E, Chang P, Dewey L, Wagner AA, Petros F, Matin SF, Tobert C, Tracy C, Patard PM, Roumiguie M, Monteiro LL, Kassouf W, Raman JD. Comparison of the Comprehensive Complication Index and Clavien-Dindo systems in predicting perioperative outcomes following radical nephroureterectomy. Transl Androl Urol 2020;9(4):1780-1785. doi: 10.21037/tau.2020.01.16 complications following partial and total nephrectomy for renal cancer in a population based sample. J Urol 2007;177:1709-14.

9. Park R, Rjepaj C, Lehman K, et al. Comparison of two indices to annotate complications after radical nephroureterectomy. Can J Urol 2017;24:9103-6.

10. Merkow RP, Ju MH, Chung JW, et al. Underlying reasons associated with hospital readmission following surgery in the United States. JAMA 2015;313:483-95.

11. Vonlanthen R, Slankamenac K, Breitenstein S, et al. The impact of complications on costs of major surgical procedures: a cost analysis of 1200 patients. Ann Surg 2011;254:907-13.

12. Mitropolous D, Artibani W, Graefen M, et al. Reporting and grading of complications after urologic surgical procedures: an ad hoc EAU guidelines panel assessment and recommendations. Eur Urol 2012;61:341-9. 